\title{
The Mediating Effect of Ethical Perception on the Relationship between Tax Service and Tax Compliance Behavior Using Baron and Kenny and Bootstrapping Method
}

\author{
Swee Kiow Tan *a, Mohd Fuad Mohd Salleh ${ }^{\mathrm{b}}$ \& Aza Azlina Md Kassim ${ }^{\mathrm{c}}$ \\ ${ }^{a}$ Faculty of Business and Finance, Universiti Tunku Abdul Rahman, \\ Kampar, Perak, Malaysia \\ ${ }^{\mathrm{b}, \mathrm{c}}$ Faculty of Business and Accountancy, Universiti Selangor, \\ Shah Alam, Selangor, Malaysia
}

Received: 10 April 2019

Revised: 22 July 2019

Accepted: 14 August 2019

\begin{abstract}
The main purpose of this study is to examine the mediating and indirect effects of ethical perception in tax service on tax compliance behaviour. The study used crosssectional survey design to collect primary data from individual taxpayers in the southern region of Peninsular Malaysia. Data was analysed with Statistical Package for the Social Science (SPSS). Results indicate that partial mediation was supported by adopting Baron and Kenny method. However, there is almost no mediation by using bootstrapping method. It showed that ethical perception of individual taxpayers differ across individuals and these differences matter in significant ways particularly in their tax compliance decisions. Therefore, IRB should provide better tax service to individual taxpayers in order to enhance their tax ethics and compliance. This may increase tax revenue and reduce the budget deficit without raising tax rates. This research results provide valuable information for the IRB and it is useful for tax policy development.
\end{abstract}

Keywords: Ethical perception, tax service, tax compliance behaviour, mediator, Baron and Kenny, bootstrapping

\subsection{Introduction}

Government's revenue comprises of various types of tax revenues. Income tax collected from individual taxpayers is one of the major sources of tax revenue. Tax evasion is a widespread phenomenon and most countries are facing the problem of non-compliance by individual taxpayers especially those that implement self-assessment systems such as Malaysia. Currently, the Malaysian government is in a budget deficit situation; hence increasing individual taxpayers' compliance behaviour would reduce the budget deficit

Corresponding author

Email: sktan@utar.edu.my 
without raising additional taxes. To overcome this issue, the researcher conducted a study to examine the mediating effect of ethical perception on the relationship between tax service provided by Inland Revenue Board (IRB) and tax compliance behaviour. This study used Baron and Kenny and bootstrapping method as both methods can work hand in hand.

Mediation is generally tested in many studies. Alternative name for mediator variable is "intervening or process variable". It is the variable that causes mediation in the correlation between the outcome (dependent variable) and the causal variable (independent variable) (Baron \& Kenny, 1986, Kenny, 2016). Baron and Kenny (1986) recommended mediation is tested over three regression models as below:

i) A regression forecasting the independent variable $(\mathrm{X})$ is related with dependent variable (Y) and contributes the value of $c$ (Model 1).

ii) A regression forecasting the independent variable $(\mathrm{X})$ is related with the mediator (M). Hence the regression coefficient contributes the value of $a$ (Model 2).

iii) A regression forecasting the outcome (Y) from both the independent variable $(\mathrm{X})$ and the mediator $(\mathrm{M})$. The regression coefficient for the predictor contributes the value of $c$ ' and the regression coefficient for the mediator contributes the value of $b$ (Model 3).

Four conditions of mediation are tested by these models: (1) the independent variable need to significantly forecast the dependent variable in model 1 ; (2) the independent variable need to significantly forecast the mediator in model $2 ;(3)$ the mediator need to significantly forecast the dependent variable in model 3; and (4) the independent variable need to forecast the dependent variable less strongly in model 3 than in model 1.

Baron and Kenny (1986) method has some shortcomings which causes the distribution of $a b$ to be non-normal and consequently is not adequately described by its variance. For example, perfect mediation is said to have occurred once the connection between the predictor and dependent variable is reduced to zero, but normally it does not take place and just a decrease in the association between the predictor and dependent variable. The problem is the deduction required in order to deduce mediation (Field, 2013). This shortcoming can be addressed by using nonparametric procedure e.g. bootstrap that make no assumptions regarding the distribution of the $a b$ product. Instead of just recording the significance of a parameter, it is also meaningful to report the bootstrap confidence interval that delivers extra evidence on the stability of a coefficient estimate. By assuming a certain level of confidence (e.g., 95\%), then the range into which the true population parameter will fall is called the confidence interval (Hair, Hult, Ringle \& Sarstedt, 2016). Bootstrapping is a non-parametric method, so it does not violate assumptions of normality, hence suggested for small sample sizes. Bootstrapping is 
conducted through resampling with replacement which is done numerous times, e.g. 1,000 times. Therefore, the indirect effect is calculated and a sampling distribution can be empirically created from each of these samples. Given this distribution, a confidence interval is calculated. The significance or non-significance of the mediation effects can be identified through this process. The researcher can be confident that the indirect effect is different from zero if zero is not in the interval, subsequently the indirect effect is statistically significant (Hayes, 2013; Preacher \& Hayes, 2004).

\subsection{Literature Review}

Tax service is an intangible product supplied by Inland Revenue Board. Taxpayers will be more willing to pay their taxes if they perceived a greater service orientation as service orientation strengthens compliance (Gangl, Muehlbacher, Groot, Goslinga, Hofmann, Kogler \& Kirchler, 2013). Malaysia has introduced electronic tax filing (e-filing) system in February 2006, which is on voluntary basis. A successful selfassessment system requires appropriate compliance among taxpayers.

Ethical perception plays an important role in the ethical decision-making process because the process begins with an individual's recognition that a decision situation has an ethical content (Wittmer, 2000). According to various studies, it appears that Malaysian individual taxpayers have high ethics and it has a significant and positive influence on compliance behaviour (Kasipillai, Noraza \& Zaimah, 2003; Ho, Loo \& Lim, 2006; Loo, Evans \& McKerchar, 2012). But different individuals may view an ethical situation differently and it varies from individual to individual. In addition, it is varied over time for the same person, so the same individual may view an ethical issue differently over time. (Daryl \& Mark 2007).

A study by Pukeliene and Kažemekaityte (2016) suggest that tax morale and the relationship between tax authority and taxpayers have a positive impact on tax behaviour in European Union countries. Another study in Canakkale find that taxpayers' trust in tax authority and their positive perception of tax authority's governance quality influence tax compliance and tax ethics positively (Serim \& Yağanoğlu, 2017). Çanakkale is a city and seaport in Turkey, but there is still lack of similar research in Malaysia. Hence, the researchers generate the conceptual framework as shown below.

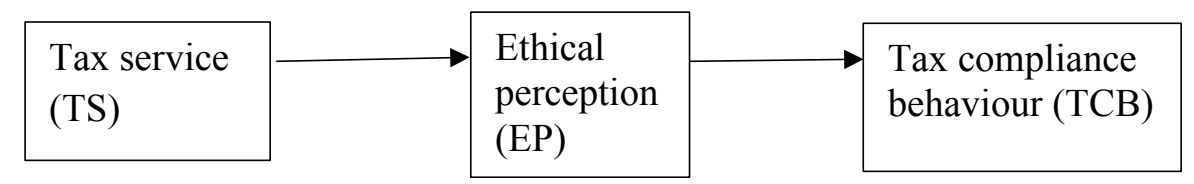

Figure 1. Research framework for determinants of tax compliance behaviour. 


\subsection{Research Methodology}

The researcher use cross-sectional survey design to collect primary data at one point in time for this study. The researcher used proportionate stratified random sampling by distributing 150 questionnaires to individual taxpayers in Johor, Negeri Sembilan and Melaka, i.e. the southern region of Peninsular Malaysia, but only 127 usable responses were received. The researcher used G*Power 3 (Faul, Erdfelder, Lang \& Buchner, 2007), a flexible statistical power analysis program to determine the sample size, with 95\% confidence interval and 0.3 effect size, it required 111 samples only. Hence, the 127 usable responses was more than enough for this study.

It is assumed the workforces' gender ratio is similar to entire population, i.e. the entire group of individual taxpayers in Malaysia. Out of 30.4 million population, 15.4 million (50.7\%) were males and 15.0 million (49.3\%) were females. For this research, the researcher chooses stratified random sampling over other types of sampling as they want to highlight a specific subgroup (gender) within the population. The researcher should be able to draw conclusions that are generalizable to the population of interest through studying the sample (Sekaran \& Bougie, 2016). This study used Statistical Package for the Social Science to analyse the data in order to obtain meaningful information.

\subsection{Data Analysis}

This study has fulfilled all four conditions as stated by Baron and Kenny (1986). By referring to attachment 1 , the output showed the results of the simple regression of Ethical Perception (EP) expected from Tax Services (TS). TS was significantly predicted relationship with $\mathrm{EP}, \mathrm{b}=.289, \mathrm{t}=2.9022, \mathrm{p}=.0044$. The $\mathrm{R}^{2}$ value indicate that TS explained $6.3 \%$ of the variance in relationship with EP and this has a positive relationship i.e. when TS increased, EP increased as well, and vice versa ( $a$-path; refer to Model 2).

Attachment 1 also show the result of the regression of Tax Compliance Behaviour (TCB) predicted by both EP and TS. It indicated that TS significantly predicted TCB even with the relationship of EP in the model, $\mathrm{b}=.2883, \mathrm{t}=4.124, \mathrm{p}<.001$; the EP is also significantly predicted by TCB, $\mathrm{b}=.1949, \mathrm{t}=3.2075, \mathrm{p}=.0017$ (b-path and $c^{\text {' }}$ path; referred Model 3). The $\mathrm{R}^{2}$ value revealed that the model explained $22.6 \%$ of the variance in TCB. The positive $b$ for EP indicated that as EP increased, TCB increased as well, and vice versa. The same indication for TS and its relation with TCB.

The $a$ and $b$ path coefficients were both statistically significance and in the direction predicted. This provided some evidence in favour of mediation. Further evidence indicates that mediation occurred as the strength of the association between TS and TCB was decreased by introducing EP, i.e. c' < c (Figure 2). Perfect mediation happens 
when c' is zero, in other words, the association between the predictor and dependent variable is absolutely wiped out by including the mediator in the model (Field, 2013). On the other hand, according to Kenny (2018), partial mediation is the situation in which the path from predictor to dependent variable is reduced in absolute size but is still different from zero when the mediator is introduced. For this study, c' $=0.2883$ (Figure 2), so partial mediation was supported. Partial mediation assumes that there is not only a significant association between the mediator and the dependent variable, but also some direct association between the independent variable and dependent variable, i.e. only part of the effect of independent variable on dependent variable is carried through mediator (Hair et al., 2016). The relationship among the three variables can be understood better by referring to Figure 1 and 2 .

To overcome the shortcoming of Baron and Kenny method, the researchers carried out additional three tests. Alternative measure of mediation is the indirect effect divided by the total effect or $a b / c$. Although this measure is theoretically informative, it is very unstable and should not be computed if $c$ is small. Kenny (2018) advise that this measure should only be computed if standardized $c$ is at least \pm .2. For this study, $c$ is 0.3446 , so it fulfils the requirement. The computation of $(0.2890 \times 0.1949) / 0.3446=$ 0.1635 indicates that it is a partial mediation. The rule of thumb to claim complete mediation is $a b / c$ should be at least 0.80 (Kenny, 2018). Other researchers have reproposed the use of $c-c^{\prime}$ as the measure of the indirect effect. They make the claim that difference in coefficients is more robust to certain forms of specification error (Imai, Keele \& Tingly, 2010). For this research, $0.3446(c)-0.2883\left(c^{\prime}\right)=0.0560$ (Figure 2).

Another test for indirect effect is the joint test of significance. It means if Step 2 (the test of $a$ ) and Step 3 (the test of $b$ ) are met, it follows that the indirect effect is likely nonzero. This research fulfil the requirements, i.e. the indirect effect is 0.0560 (Figure 2). This simple method, seems to work rather well (Fritz \& MacKinnon, 2007) but is hardly used as the definitive test of the indirect effect. Nonetheless, Fritz, Taylor, and MacKinnon (2012) strongly advised that researchers should use this test in conjunction with other tests. Furthermore, the simulation results by Hayes and Scharkow (2013) argue that this test does about as well as a bootstrap test. Additionally, this test provides a relatively straightforward way to determine the power of the test of the indirect effect. The major drawback with this approach is that it does not provide a confidence interval for the indirect effect. Hence, to overcome this drawback, the researcher performs bootstrapping test as well.

Attachment 1 also indicate the result of indirect effect using bootstrap method on 1,000 samples with replacement from the data, re-estimate mediation model and calculated standard errors $(a \times b)$ within each bootstrap sample. The results of standard errors are then used to construct confidence interval (CI). It showed the indirect effect with $95 \%$ CI, the lower bound of the bootstrap CI was .0246 and the upper bound was .1311. 
As the $95 \%$ CI did not include zero, the indirect effect is statistically significant and mediation was supported. The variance accounted for (VAF) in bootstrapping decides the size of the indirect effect in relation to the total effect (i.e., direct effect + indirect effect). Thus, it can be concluded that the variance of the dependent variable is directly explained by the independent variable. One can conclude that (almost) no mediation takes place if $\mathrm{VAF}<20 \%$, partial mediation occurred if $20 \% \leq \mathrm{VAF} \leq 80 \%$ and when VAF $>80 \%$, one can assume a full mediation (Hair et al., 2016). The VAF is $16.35 \%$, i.e. slightly $<20 \%$, this situation can be regarded as almost no mediation.

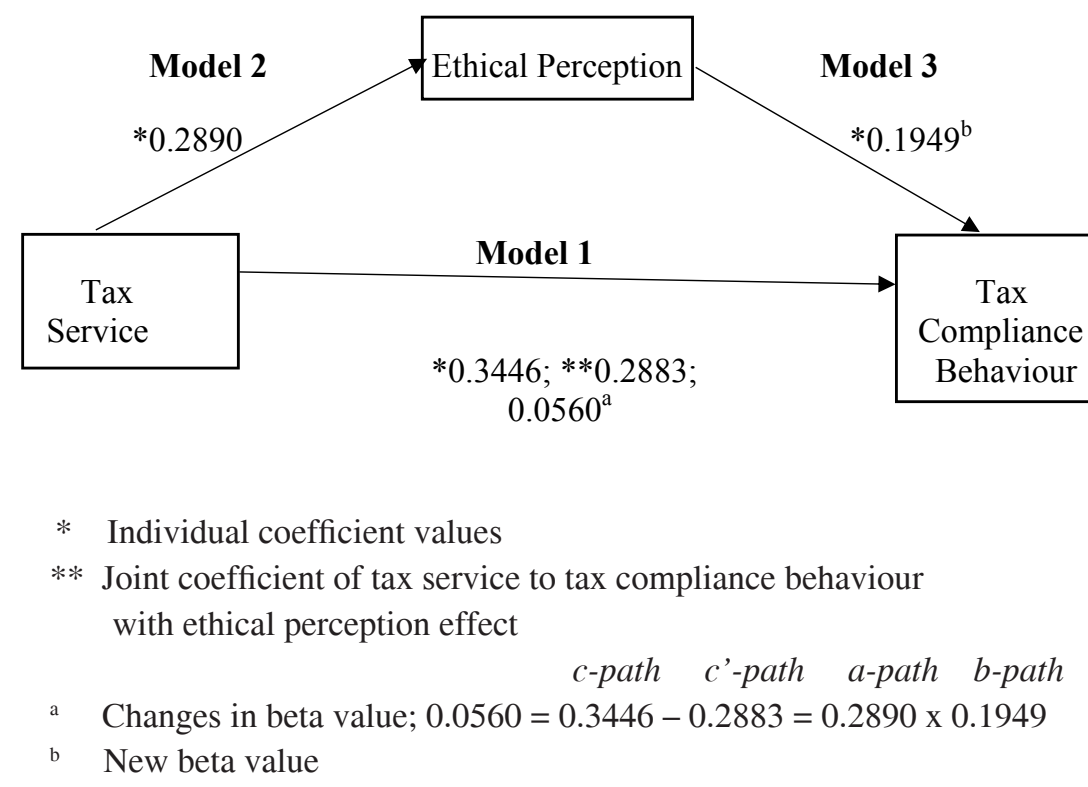

Figure 2. Mediation effect (Ethical perception) on the relationship between tax service and tax compliance behaviour.

\subsection{Conclusion}

Mediation can be a tremendously useful and influential statistical test. It continues to be the most frequent analysis conducted using the assumptions of Baron and Kenny. Due to some shortcomings, bootstrapping is becoming more popular in testing mediation. Both methods work hand in hand to test whether the predictor affects outcome after the inclusion of mediator. For this study, partial mediation was supported by adopting Baron and Kenny method but almost no mediation with the adoption of bootstrapping method. The researchers perform additional three tests to overcome the shortcomings 
and justified the results by using the Baron and Kenny method. It indicated that individual taxpayers have different ethical perception and these differences do matter in their tax compliance decisions. One of the reason that influence ethical perception is tax service provided by Inland Revenue Board (IRB). A good tax service includes positive interaction, short duration to respond to clients' queries and sufficient technical knowledge by IRB staffs, a user friendly and clear instructions in online tax filing and a conducive physical environment. The implication of these results is that IRB should provide better tax service quality to individual taxpayers to enhance their tax ethics and compliance behavior. This will increase tax revenue and reduce budget deficit without raising tax rates.

\section{Acknowledgement}

This research was funded by UTAR Research Fund.

\section{References}

Baron, R. M., \& Kenny, D. A. (1986). The moderator-mediator variable distinction in social psychological research: Conceptual, strategic and statistical considerations. Journal of Personality and Social Psychology, 51, 1173-1182.

Daryl M. Guffey \& Mark W. McCartney, (2007). The perceived importance of an ethical issue as a determinant of ethical decision-making for accounting students in an academic setting. Accounting Education: An International Journal 17(3), $327-348$.

Faul, F., Erdfelder, E., Lang, A.-G. \& Buchner, A. (2007). G*Power 3: A flexible statistical power analysis program for the social, behavioral, and biomedical sciences. Behavior Research Methods, 39, 175-191.

Field, A. (2013). Discovering statistics using IBM SPSS statistics. Sage.

Fritz, M. S., \& MacKinnon, D. P. (2007). Required sample size to detect the mediated effect. Psychological Science, 18(3), 233-239.

Fritz, M. S., Taylor, A. B., \& MacKinnon, D. P. (2012). Explanation of two anomalous results in statistical mediation analysis. Multivariate behavioral research, 47(1), 61-87.

Gangl, K., Muehlbacher, S., de Groot, M., Goslinga, S., Hofmann, E., Kogler, C \& Kirchler, E. (2013). "How can I help you?" Perceived service orientation of tax authorities and tax compliance. FinanzArchiv: Public Finance Analysis, 69(4), 487-510.

Hair Jr, J. F., Hult, G. T. M., Ringle, C.M., \& Sarstedt. M (2016). A primer on partial least squares structural equation modeling (PLS-SEM). Sage Publications.

Hayes, A. F., 2013. Introduction to mediation, moderation, and conditional process analysis: A regression-based approach. New York: Guilford Press. 
Hayes, A. F., \& Scharkow, M. (2013). The relative trustworthiness of inferential tests of the indirect effect in statistical mediation analysis: Does method really matter?. Psychological Science, 24(10), 1918-1927.

Ho, J. K., Loo, E. C., \& Lim, K. P. (2006). Perspective of non-taxpayers' perception on issues of ethics and equity in tax compliance. Malaysian Accounting Review, 5(2), 47-59.

Imai, K., Keele, L., \& Tingley, D. (2010). A general approach to causal mediation analysis. Psychological Methods, 15(4), 309.

Kasipillai, J., Noraza, M. U. \& Zaimah, Z. A. (2003). How do moral value influence tax compliance behaviour? Findings from a survey: The Chartered Secretary Malaysia, June, 10-15.

Kenny, D. A. (2018). Mediation, http://davidakenny.net/cm/mediate.htm

Loo, E. C., Evans, C., \& McKerchar, M. A. (2012). Challenges in understanding compliance behaviour of taxpayers in Malaysia. Asian Journal of Business and Accounting, 3(2), 2010.

Preacher, Kristopher J.; Hayes, Andrew F. (2004). "SPSS and SAS procedures for estimating indirect effects in simple mediation models". Behavior Research Methods, Instruments, and Computers. 36(4): 717-731.

Pukeliene, V., \& Kažemekaityte, A. (2016). Tax behaviour: Assessment of tax compliance in European Union Countries. Ekonomika, 95(2), 30-56.

Sekaran, Uma \& Bougie, Roger. (2016). Research methods for business: A skillbuilding approach ( $7^{\text {th }}$ edition). John Wiley and Sons Ltd.

Serim, N., \& Yağanoğlu, N. Y. (2017). Good governance and tax compliance: An ordered probit application in Çanakkale. Journal of Entrepreneurship and Development, 12(2), 51-64. 
The Mediating Effect of Ethical Perception on the Relationship between Tax Service and Tax Compliance Behavior

Using Baron and Kenny and Bootstrapping Method: $41-49$

\section{Attachment 1}

Outcome: EP

Model Summary

$\begin{array}{ccccccc}R & \text { R-sq } & \text { MSE } & \text { F } & \text { df1 } & \text { df2 } & p \\ .2513 & .0631 & .6075 & 8.4228 & 1.0000 & 125.0000 & .0044\end{array}$

Model

$\begin{array}{lrlccccc} & \text { coeff } & \text { se } & t & \mathrm{p} & \text { LLCI } & \text { ULCI } & \\ \text { Constant } & 1.9365 & .3532 & 5.4829 & .0000 & 1.2375 & 2.6356 & \\ \text { TSS } & .2890 & .0996 & 2.9022 & .0044 & .0919 & .4862\end{array}$ a-path

Outcome: TCB

Model Summary

$\begin{array}{ccrcccc}R & \text { R-sq } & \text { MSE } & \text { F } & \text { df1 } & \text { df2 } & p \\ .4755 & .2261 & .2803 & 18.1145 & 2.0000 & 124.0000 & .0000\end{array}$

Model

\begin{tabular}{|c|c|c|c|c|c|c|}
\hline con & $\begin{array}{r}\text { coeff } \\
1.7077\end{array}$ & $\begin{array}{c}\text { se } \\
.2672\end{array}$ & $\begin{array}{c}t \\
6.3905\end{array}$ & $\begin{array}{c}p \\
.0000\end{array}$ & $\begin{array}{l}\text { LLCI } \\
1.1788\end{array}$ & $\begin{array}{l}\text { ULCI } \\
2.2366\end{array}$ \\
\hline$E P$ & .1949 & .0608 & 3.2075 & .0017 & .0746 & .3151 \\
\hline TS & .2883 & .0699 & 4.1240 & .0001 & .1499 & .4266 \\
\hline
\end{tabular}

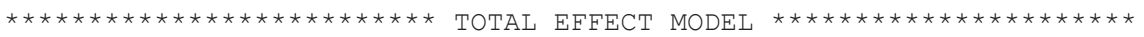

Outcome: TCB

Model Summary

$\begin{array}{ccccccc}R & \text { R-sq } & \text { MSE } & F & \text { df1 } & \text { df2 } & p \\ .4024 & .1619 & .3011 & 24.1470 & 1.0000 & 125.0000 & .0000\end{array}$

Model

\begin{tabular}{|c|c|c|c|c|c|c|}
\hline I & $\begin{array}{r}\text { coeff } \\
2.0851\end{array}$ & $\begin{array}{l}\text { se } \\
2487\end{array}$ & $\begin{array}{c}t \\
8.3846\end{array}$ & $\begin{array}{c}p \\
.0000\end{array}$ & $\begin{array}{c}\text { LLCI } \\
1.5929\end{array}$ & $\begin{array}{c}\text { ULCI } \\
2.5773\end{array}$ \\
\hline & .3446 & .0701 & 4.9140 & .0000 & .2058 & .4834 \\
\hline
\end{tabular}

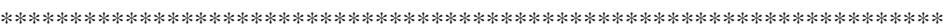

Completely standardized indirect effect of X on $\mathrm{Y}$

\begin{tabular}{cccccc} 
& Effect & Boot & SE & BootLLCI & BootULCI \\
EP & .0658 & .0263 & .0246 & .1311 & \multirow{2}{*}{ Bootstrapping } \\
& & & & \\
Ratio of indirect to total effect of X on $\mathrm{Y}$ & \\
& Effect & Boot SE & BootLLCI & BootULCI & \\
EP & .1635 & .0711 & .0509 & .3452 & Variance accounted for
\end{tabular}

